\title{
Strength Characteristic of Lateritic Soil Replaced by Recycled Asphalt Pavement
}

\author{
Weeraya Chimoye \\ Associate Prof. \\ School of Engineering, Thammasat University \\ Phatumthani, Thailand
}

\author{
Tustha Sriwalai \\ School of Engineering, Thammasat University \\ Phatumthani, Thailand
}

\begin{abstract}
The objective of this project is to study the physical, compaction, and strength properties of lateritic soil, recycled asphalt, and the combination of them according to subbase material standard of Department of Highways, DH.-S 205/2532. The used lateritic soil is selected material which the grain size distribution base on the standard of Type A, Type B, and Type E. The lateritic soil Type $E$ was mixed with the recycled asphalt pavement (RAP) to be material ARAP and BRAP. The modified compaction test of all five types of the material were carried out. It is found that the RAP can improve the compaction behavior of the lateritic soil. The maximum dry density increased and the optimum water content decreased when mixed with the RAP. The compacted all materials were prepared for CBR test with $\mathbf{9 5 \%}$ of maximum dry density with optimum water content and optimum water content $+2 \%$. It is found that the CBR of the mixed material decreased rapidly when compared with the same type of lateritic soil. It can be seen that recycled asphalt pavement cannot improve the strength of the lateritic soil. This cause by size of the recycled asphalt pavement is the size of packed gravel by asphalt and break out to be smaller size after compaction. Compared with the subbase standard, the unsoaked CBR of all types of materials were higher than 25 which passed the standard.
\end{abstract}

Keywords-Recycled concrete, recycled asphalt pavement, lateritic soil, subbase

\section{INTRODUCTION}

In highway or road construction, the lateritic soil or crushed rock are commonly used as the embankment fill or subbase materials. For the pavement, both asphaltic pavement (AP) and concrete pavement (CP) are typical pavements for highway or rural road in Thailand. With the construction growth for urban area development, tremendous amounts of natural materials are consumed in urban industry and huge energy is used. And also the amount of waste materials generated from road maintenance or re-constructed during service period is increasing. The construction solid waste materials have become one of the main concerns of the environmental concern. Reusing recycled construction and demolition $(\mathrm{C} \& \mathrm{D})$ materials in transportation infrastructure construction can benefit environmental and economic aspects. The utilization of the recycled construction materials has been considered as a significant solution to minimize the use of natural resources and reduce the cost for waste management. [1]. There are at least 3 advantages to use recycled construction material as natural resource preservation, construction expense reduce due to the transportation and reduction of the accumulated $C \& D$ waste materials in deposits [2]. Recently recycled asphaltic pavement (RAP) either, itself or stabilized with cement have been studied for used as base and subbase layers $[2,3,4]$. The objective of this research is to study the strength characteristic of lateritic soil replaced by the recycled asphaltic pavement (RAP). The effect of RAP on compaction behavior, strength and swelling were investigated.

\section{MATERIALS USE}

\section{A. Lateritic Soil}

The lateritic soil used in this research is the selected grain size in order to classify as Type A, Type B and Type E according to subbase material standard of Department of Highways, DH.-S 205/2532 of Thailand [5]. The grain size distributions of each types are shown in Fig. 1. The nature of the lateritic soil is shown in Fig. 2. The lateritic soil has liquid limit as $29.8 \%$, plastic limit as $19.6 \%$ and plasticity index as $10.2 \%$ which pass the criteria of the subbase standard. The specific gravity is 2.72 .

\section{B. Recycled asphalt pavements (RAP)}

The recycled asphalt pavements were supplied from the Daokanong - ThaRue Highway as shown in Fig. 3. The asphaltic pavement was Wearing course standard mixed with $60-70$ penetration grade of Industrial standard of Thailand. The RAP was selected by sieving passing 1" and retained on $3 / 8$ ".

\section{METHODOLOGY}

The lateritic soil Type E were mixed with RAP to be the Type A and B as the same grain size distribution as shown in Fig.1, named ARAP and BRAP respectively. The RAP was sieved with the selected grained size as Type A. The lateritic soil and the lateritic soil mixed with the RAP and the RAP were compacted with modified standard. The behavior of the compaction curves is shown in Fig. 4. The maximum dry densities $\left(\rho_{\mathrm{dmax}}\right)$ and the optimum water contents (OPT) of all types of material were shown in Table 1 . It can be seen that the RAP can be compacted with least optimum water content and highest maximum dry density. The RAP can improve the compaction property of the lateritic soil by increasing the maximum dry density and decreasing the optimum water content. From the results of the compaction, the unsoaked and soaked CBR of all types of material were test at optimum water content and optimum water content $+2 \%$ and the dry density over than $95 \%$ of maximum dry density. For each condition, two samples were tested for repeated. Fig. 5 shows the dry density of all CBR samples which pass the criteria of testing. 


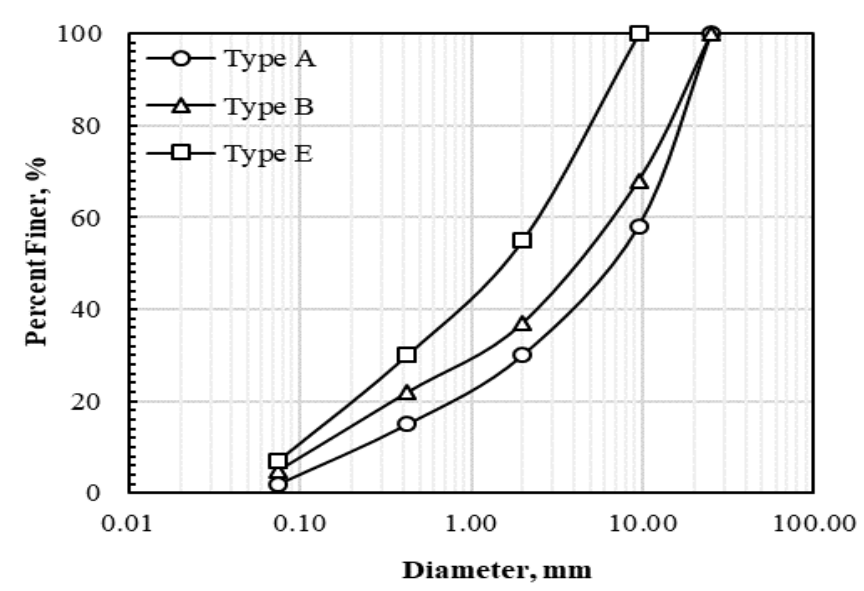

Fig. 1 Grain size of selected soil Type A, B and E.

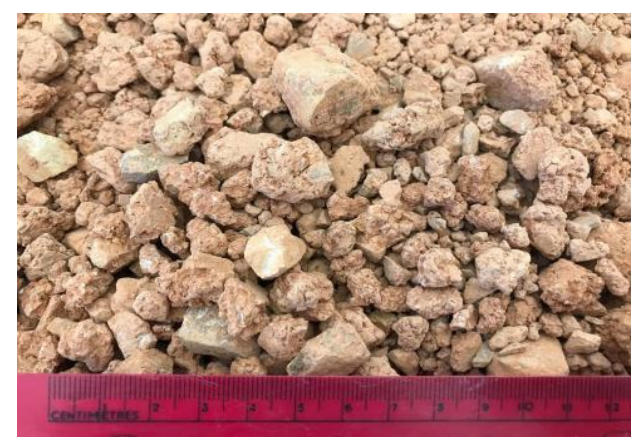

Fig. 2 The natural lateritic soil.

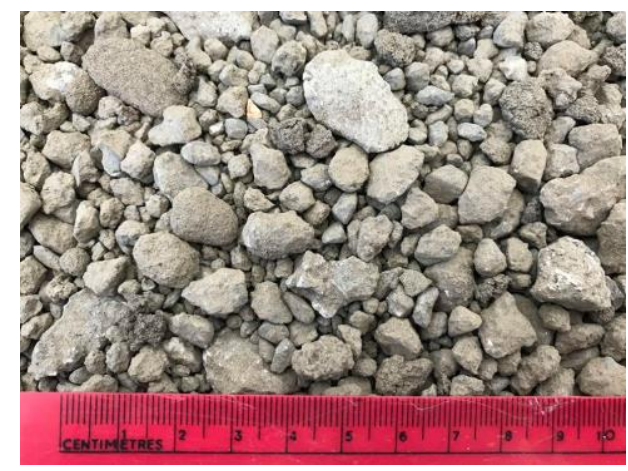

Fig. 3 The recycled asphalt pavement.

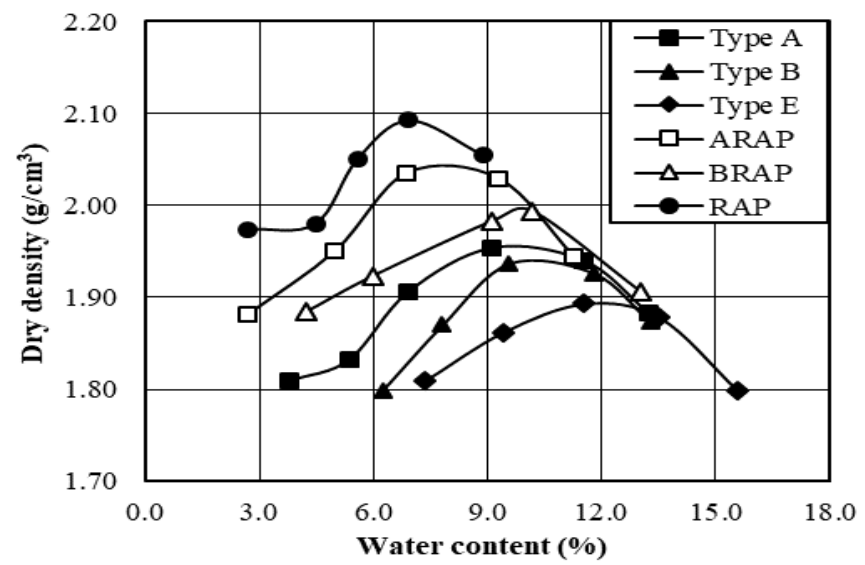

Fig. 4 Compaction curve of lateritic soil mixed with RAP
TABLE I. MAXIMUM DRY DENSITY AND OPTIMUM WATER CONTENT

\begin{tabular}{|l|c|c|c|}
\hline Type & $\begin{array}{c}\text { Soil } \\
\text { condition }\end{array}$ & $\begin{array}{c}\rho_{\mathrm{dmax}} \\
\mathrm{g} / \mathrm{cm}^{3}\end{array}$ & $\begin{array}{c}\text { OPT } \\
\%\end{array}$ \\
\hline Type A & Lateritic soil & 1.956 & 9.6 \\
\hline Type B & Lateritic soil & 1.940 & 10.2 \\
\hline Type E & Lateritic soil & 1.894 & 12.0 \\
\hline ARAP & $\begin{array}{c}\text { Type E }+ \\
\text { RAP }\end{array}$ & 2.044 & 7.9 \\
\hline BRAP & $\begin{array}{c}\text { Type E }+ \\
\text { RAP }\end{array}$ & 1.996 & 9.8 \\
\hline RAP & RAP & 2.092 & 6.9 \\
\hline
\end{tabular}

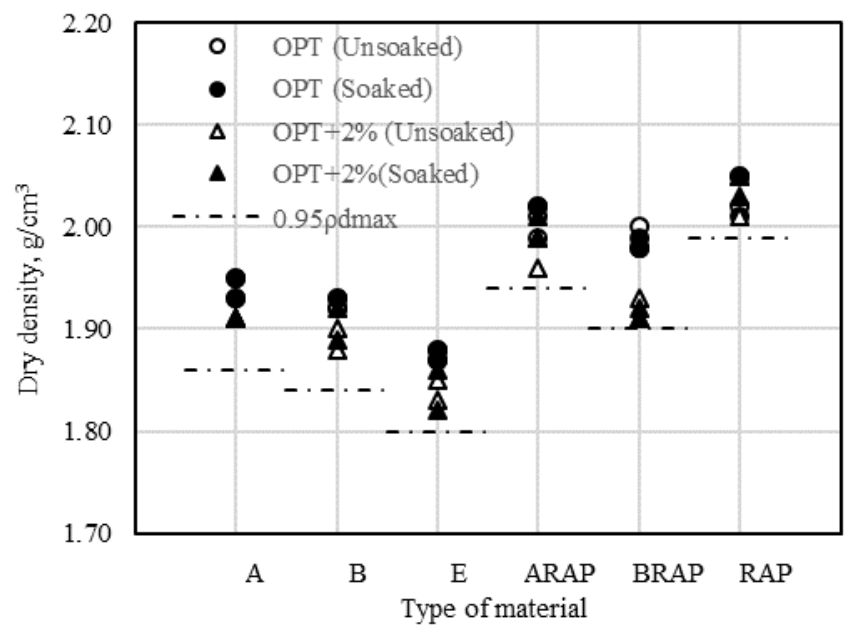

Fig. 5 Dry density of all CBR samples.

\section{RESULTS}

\section{A. Compaction tests}

Fig. 6 shows the maximum dry density of all types of material. It is found that the maximum dry densities of the lateritic soil increased when mixed with recycled asphalt pavement. For the optimum water content, it is found that the optimum water content decreased when mixed with recycled asphalt as shown in Fig. 7. It means the recycled asphalt pavement can improve the compaction behavior of the lateritic soil.

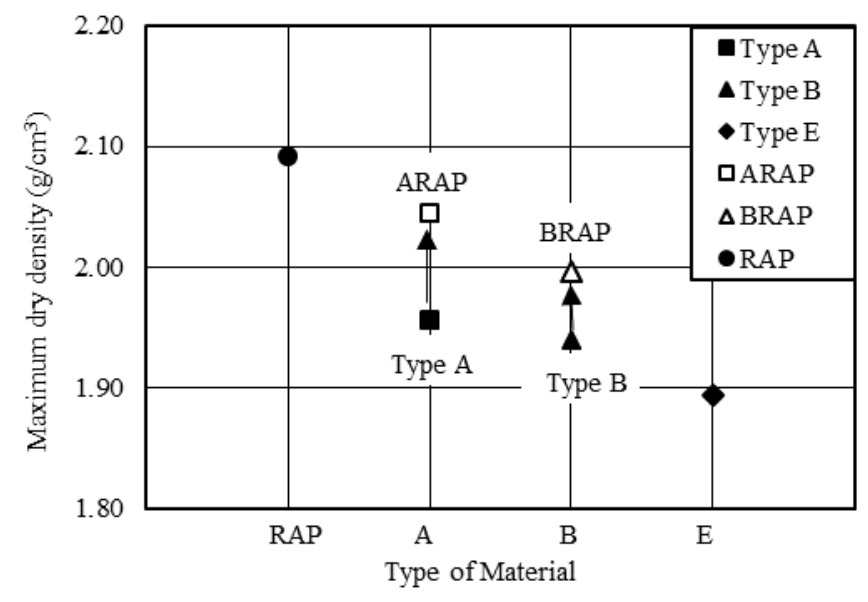

Fig. 6 Maximum dry density with type of material 


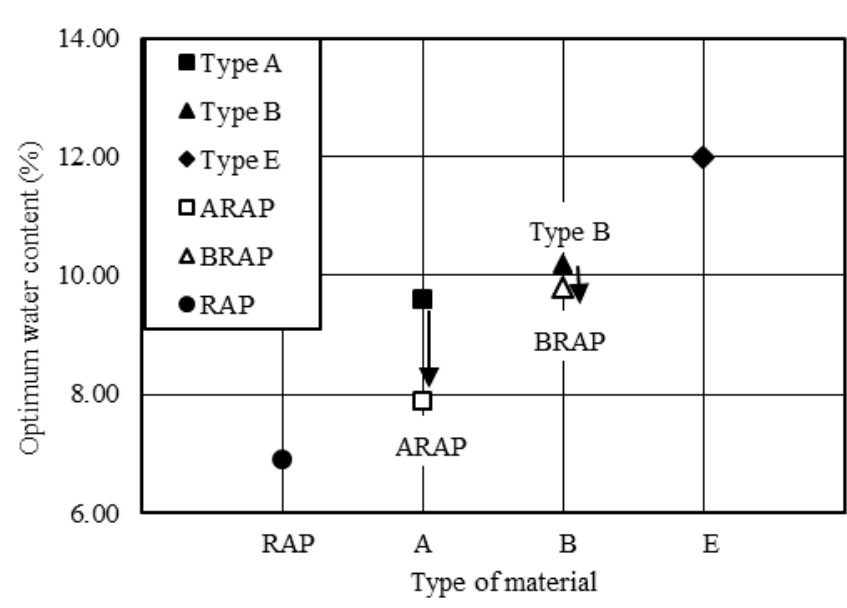

Fig. 7 Optimum water content with type of material

\section{B. $C B R$}

Fig. 8 and 9 shows the typical stress-penetration relationship from the CBR test of Type A and ARAP, respectively. It can be seen that the stress-penetration curve of the lateritic soil mixed with RAP is flatter than that of lateritic soil. This means that the RAP does not improve the strength of the lateritic soil. Table 2 shows the value of CBR of all types of the material.

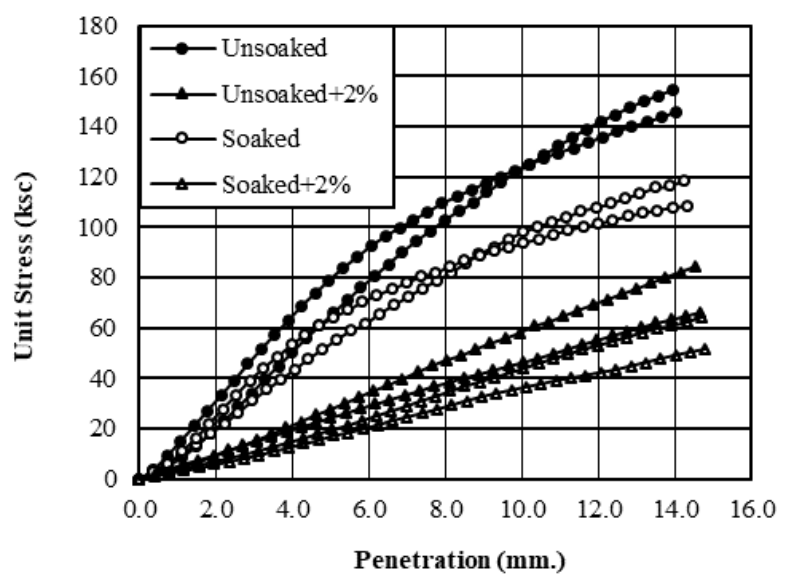

Fig. 8 Stress-penetration from CBR test of Type A

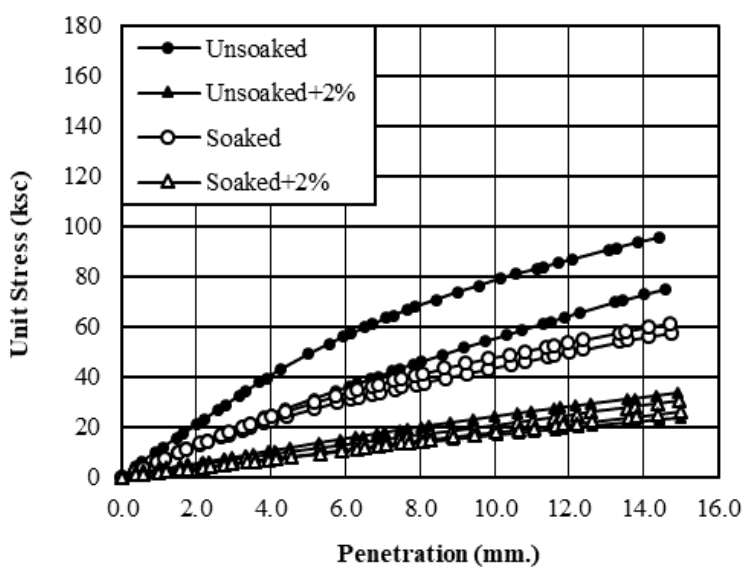

Fig. 9 Stress-penetration from CBR test of ARAP

\section{TABLE II. CBR VALUE OF ALL MATERIAL}

\begin{tabular}{|c|c|c|c|}
\hline \multirow{2}{*}{ Type } & \multirow{2}{*}{ Condition } & \multicolumn{2}{|c|}{ CBR } \\
\hline & & OPT & $\mathrm{OPT}+2 \%$ \\
\hline \multirow{4}{*}{ Type A } & Unsoaked 1 & 62.58 & 26.55 \\
\hline & Unsoaked 2 & 79.65 & 22.76 \\
\hline & Soaked 1 & 51.20 & 16.12 \\
\hline & Soaked 2 & 60.69 & 18.96 \\
\hline \multirow{4}{*}{ Type B } & Unsoaked 1 & 66.38 & 27.50 \\
\hline & Unsoaked 2 & 60.69 & 29.40 \\
\hline & Soaked 1 & 45.51 & 19.91 \\
\hline & Soaked 2 & 53.10 & 22.76 \\
\hline \multirow{4}{*}{ Type E } & Unsoaked 1 & 49.31 & 18.96 \\
\hline & Unsoaked 2 & 53.10 & 15.17 \\
\hline & Soaked 1 & 32.24 & 7.11 \\
\hline & Soaked 2 & 30.34 & 7.68 \\
\hline \multirow{4}{*}{ ARAP } & Unsoaked 1 & 45.51 & 17.07 \\
\hline & Unsoaked 2 & 29.40 & 8.53 \\
\hline & Soaked 1 & 24.65 & 10.62 \\
\hline & Soaked 2 & 28.45 & 8.72 \\
\hline \multirow{4}{*}{ BRAP } & Unsoaked 1 & 26.55 & 8.53 \\
\hline & Unsoaked 2 & 28.45 & 7.78 \\
\hline & Soaked 1 & 21.81 & 6.16 \\
\hline & Soaked 2 & 21.81 & 4.74 \\
\hline \multirow{4}{*}{ RAP } & Unsoaked 1 & 29.40 & 22.76 \\
\hline & Unsoaked 2 & 37.93 & 32.24 \\
\hline & Soaked 1 & 22.76 & 30.34 \\
\hline & Soaked 2 & 30.34 & 26.55 \\
\hline
\end{tabular}

From the CBR results it can be seen that when mixed the RAP with the lateritic soil, both to be ARAP or BRAP, the CBR decreased that means the RAP did not improve the strength of lateritic soil [2]. This cause by the grain size of the RAP is packed due to the asphalt at the initial and it is broken after compacted as shown in Fig. 10. The grain size distribution of the ARAP and BRAP after CBR test has more fine grain especially the percent finer of $3 / 8$ " increases rapidly from the grain size before test. When the asphalt was removed from the RAP, it is found that the percent asphalt was about $20 \%$ and the grain size of RAP is in the range of $12.5 \mathrm{~mm}$ for pavement standard which means the actual size of particle is less than $12.5 \mathrm{~mm}$. The CBR of OPT $+2 \%$ of all conditions decreased rapidly compared with that of OPT except for RAP case. Since the RAP has a little fine particle and no plasticity so when compact with the high water content, the water came out as the surface of the sample as shown in Fig. 11. Compared with the subbase and base material standard of Department of Highways, the CBR of the all conditions did not pass the base material standard. For the unsoaked sample, in case of optimum water content of all conditions, the CBRs 
were more than 25 which passed the subbase material standard. For others condition, the CBRs were about 25 and less which not pass the standard as shown in Fig. 12.

\section{Swelling of samples}

Fig. 13 shows swelling of the soaked CBR sample. It can be seen that the swelling of all the cases are quite low less than $0.6 \%$. The swelling of lateritic soil Type $\mathrm{E}$ is the highest with the large difference between OPT samples and OPT $+2 \%$ samples. Since the lateritic soil Type E contained with high amount of fine grained soil. For the RAP, there is no swelling since it has no plasticity and has small about of fine grain soil.

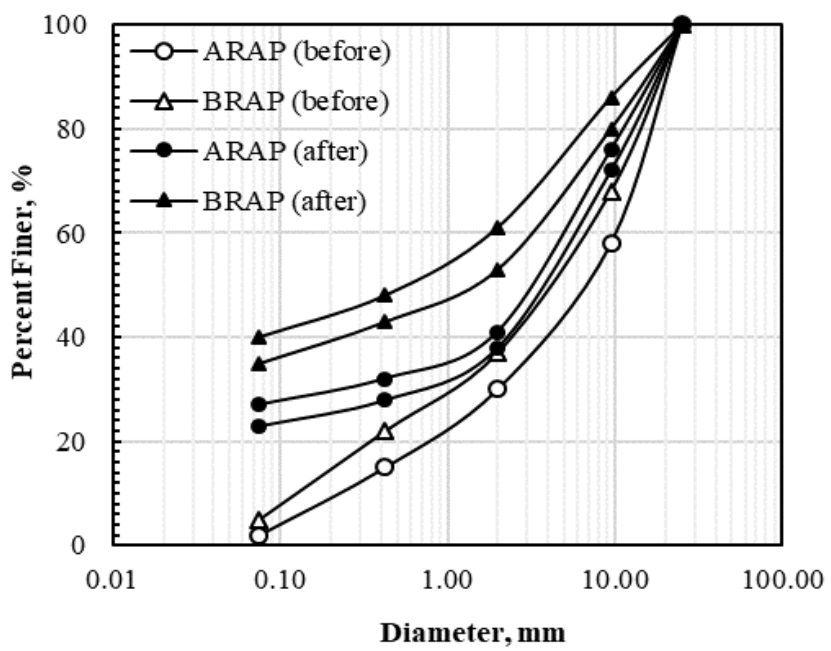

Fig. 10 Grain size distribution before and after CBR test.

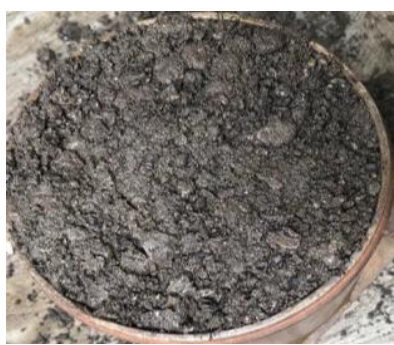

a) CBR sample at OPT

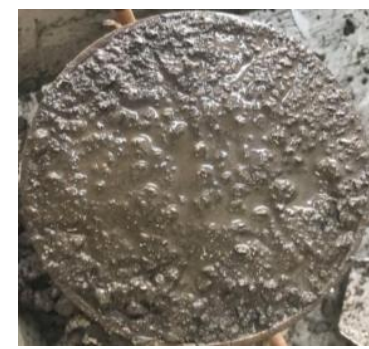

b) CBR sample at OPT $+2 \%$
Fig. 11 CBR sample of RAP

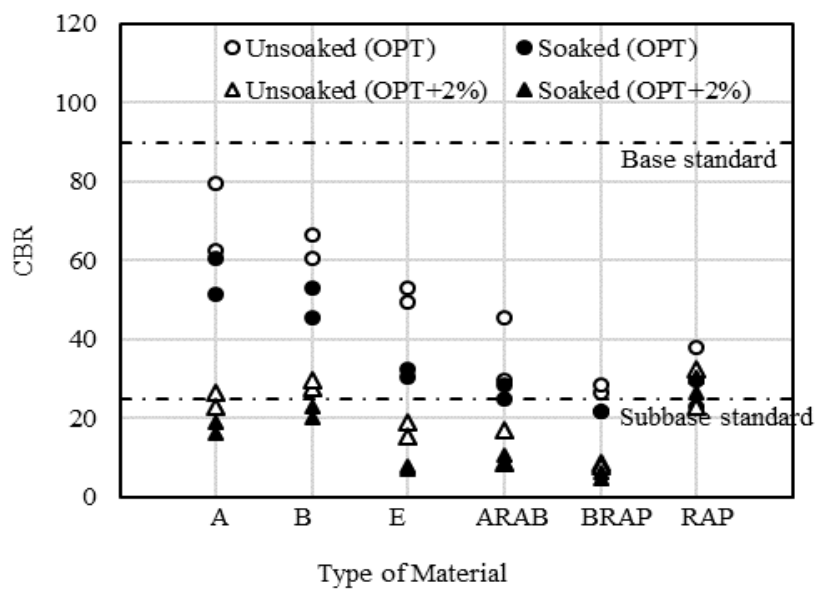

Fig. 12 CBR of all samples.

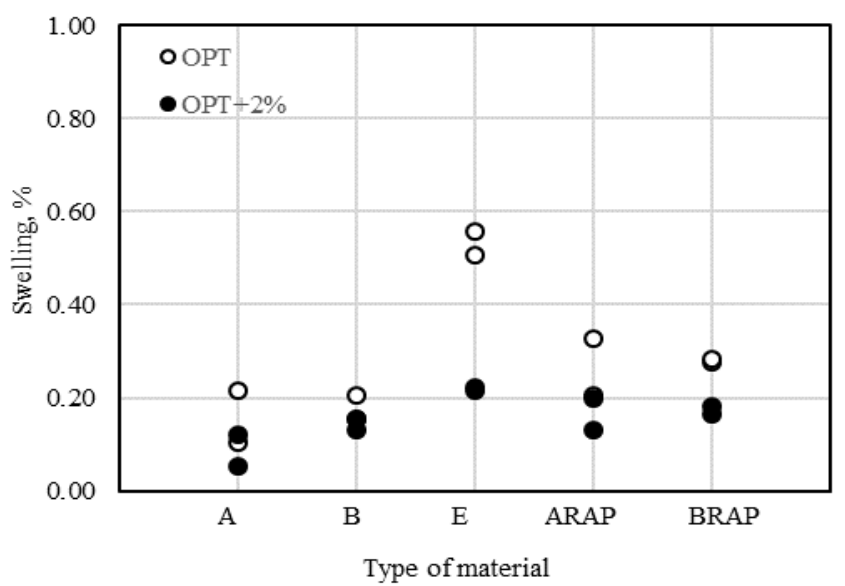

Fig. 13 Swelling of the soaked sample.

\section{CONCLUSION}

From the results, it can be concluded that

1. The RAP can improve the compaction properties of the lateritic soil by increasing the maximum dry density and decreasing the optimum water content.

2. The RAP did not improve the strength of the lateritic soil. The CBR of lateritic soil mixed with RAP decreased when compare with the lateritic soil itself. The RAP reduced the swelling of the lateritic soil in case of OPT, but has little effect with OPT $+2 \%$.

3. Compared with the subbase standard of Highway Department, it is found that the unsoaked CBRs of all condition with OPT were higher than $25 \%$ which passed the standard. For soaked CBR with OPT, almost all condition passed the standard, except BRAP type. For the condition of OPT $+2 \%$, the CBRs of all the conditions did not pass the standard.

\section{ACKNOWLEDGMENT}

Authors would like to thank Mr.Sanhant Dulpinitthamma and Mr.Apidet Tunvutgijaroen for carry out the laboratory test. Authors also acknowledge Faculty of Engineering, Thammasat University for facilitating for the laboratory equipment.

\section{REFERENCES}

[1] M. Arshat and M.F. Ahmed, "Potential use of reclaimed asphal pavement and recycled concrete aggregate in base/subbase layers of flexible pavements" Construction and Building Materials, 151, pp. 8397, 2017.

[2] J. Suebsuk, B. Khunviset, A. Sukhsan, C. Suksiripattanapong and K Chaidechatorn, "Unconfined compressive strength and microstructure of marginal lateritic soil improved by recycled asphalt pavement and cement" Ladkrabang Engineering Journal, Vol. 33, No.2, pp. 111-116, 2016.

[3] S. Fatemi and R. Imaninasab, "Performance evaluation of recycled asphalt mixtures by construction and demolition waste materials" Construction and Building Materials, 120, pp. 450-456, 2016

[4] A. Arulrajah, M.M. Disfani, S. Horpibulsuk and C. Suksiripattanapong, "Physical properties and shear strength responses of recycled construction and demolition materials in unbound pavement base/subbase applications" Construction and Building Materials, 58, pp. $245-257,2014$

[5] Department of Highway, "Stardard No. DH-S 205/2532 Highway subbase material, 1989. 